\title{
Chemical Species, Micromorphology, and XRD Fingerprint Analysis of Tibetan Medicine Zuotai Containing Mercury
}

\author{
Cen Li, ${ }^{1,2}$ Hongxia Yang, ${ }^{1,2}$ Yuzhi Du, ${ }^{1,2}$ Yuancan Xiao, ${ }^{1,2}$ Zhandui, $^{3}$ Sanglao, \\ Zhang Wang, ${ }^{5}$ Duojie Ladan, ${ }^{6}$ Hongtao Bi, ${ }^{1,2}$ and Lixin Wei ${ }^{1,2}$ \\ ${ }^{1}$ Pharmacology and Safety Evaluation Key Laboratory of Tibetan Medicine in Qinghai Province, Northwest Institute of \\ Plateau Biology, Chinese Academy of Sciences, Xining, Qinghai 810008, China \\ ${ }^{2}$ Key Laboratory of Tibetan Medicine Research, Chinese Academy of Sciences, Xining, Qinghai 810008, China \\ ${ }^{3}$ Tibetan Traditional Medical College, Lhasa, Tibet 850000, China \\ ${ }^{4}$ Gansu Province Academy of Tibetan Medicine, Hezuo, Gansu 747000, China \\ ${ }^{5}$ Aba Prefecture Tibetan Medicine Hospital, Maerkang, Sichuan 624000, China \\ ${ }^{6}$ Qinghai Province Tibetan Medicine Hospital, Xining, Qinghai 810007, China
}

Correspondence should be addressed to Lixin Wei; lxwei@nwipb.cas.cn

Received 20 March 2016; Accepted 4 July 2016

Academic Editor: Patrick J. Bednarski

Copyright (C) 2016 Cen Li et al. This is an open access article distributed under the Creative Commons Attribution License, which permits unrestricted use, distribution, and reproduction in any medium, provided the original work is properly cited.

Zuotai ( $g$ Tso thal) is one of the famous drugs containing mercury in Tibetan medicine. However, little is known about the chemical substance basis of its pharmacodynamics and the intrinsic link of different samples sources so far. Given this, energy dispersive spectrometry of X-ray (EDX), scanning electron microscopy (SEM), atomic force microscopy (AFM), and powder X-ray diffraction (XRD) were used to assay the elements, micromorphology, and phase composition of nine Zuotai samples from different regions, respectively; the XRD fingerprint features of Zuotai were analyzed by multivariate statistical analysis. EDX result shows that Zuotai contains $\mathrm{Hg}, \mathrm{S}, \mathrm{O}, \mathrm{Fe}, \mathrm{Al}, \mathrm{Cu}$, and other elements. SEM and AFM observations suggest that Zuotai is a kind of ancient nanodrug. Its particles are mainly in the range of $100-800 \mathrm{~nm}$, which commonly further aggregate into 1-30 $\mu \mathrm{m}$ loosely amorphous particles. XRD test shows that $\beta$-HgS, $\mathrm{S}_{8}$, and $\alpha-\mathrm{HgS}$ are its main phase compositions. XRD fingerprint analysis indicates that the similarity degrees of nine samples are very high, and the results of multivariate statistical analysis are broadly consistent with sample sources. The present research has revealed the physicochemical characteristics of Zuotai, and it would play a positive role in interpreting this mysterious Tibetan drug.

\section{Introduction}

Tibetan medicine is one of the world's existing traditional medicines having completely medical theory, with more than 2000 years' phylogeny [1-3]. Zuotai ( $g$ Tso thal), known as "King of Nectar's Essence," is one of the most famous and important drugs in traditional Tibetan medicine [4-7]. It is a kind of black-blue powder with inimitable curative effect and is obtained from liquid silver (mercury), sulfur, Nengchi Eight Metals, Nengchi Eight Minerals, and other natural drugs through special processing technology by senior Tibetan medicine practitioners [4-6, 8-10]. Zuotai generally is not used alone, but it is usually used as an adjuvant with other compound drugs $[6,11]$. And the doctors of traditional Tibetan medicine have been thinking that Zuotai could enhance the efficacy and reduce the toxicity of other drugs [6, 11]. Zuotai has already been used as a key component of Renqing series drugs in Tibetan medicine for 1300 years [12]. By now, it is still used to prepare "Renqing Mangjue," "Renqing Changjue," "Rannasangpei," "Qishiwei Songshi Wan," "Shanhu Qishiwei Wan," "Zuota Demazi," "Zuozhu Daxi," "Dangzuo," and other preparations [5, 11, 12]. These formulations are mainly applied to treat stroke, paralysis, hypertension, neurological disorders, cardiovascular disorders, liver and gallbladder disease, impotence, gastrointestinal diseases, tumors, and so on $[5,6,8]$. 
TABLE 1: Source of nine Zuotai samples.

\begin{tabular}{|c|c|c|}
\hline Number & Sample source & Comments \\
\hline$\# 1$ & Aba Prefecture Tibetan Medicine Hospital, Maerkang, Sichuan, China & Collected on November 11, 2010 \\
\hline \#2 & Gan'na Prefecture Tibetan Medicine Hospital, Hezuo, Gansu, China & Collected on November 2, 2010 \\
\hline$\# 3$ & $\begin{array}{c}\text { The Company of Tibetan Medicine of Tibetan Traditional Medical College, } \\
\text { Lhasa, Tibet, China }\end{array}$ & Processed in August 2006 \\
\hline$\# 4$ & $\begin{array}{c}\text { The Company of Tibetan Medicine of Tibetan Traditional Medical College, } \\
\text { Lhasa, Tibet, China }\end{array}$ & Processed in September 2007 \\
\hline$\# 5$ & $\begin{array}{c}\text { The Company of Tibetan Medicine of Tibetan Traditional Medical College, } \\
\text { Lhasa, Tibet, China }\end{array}$ & Processed in September 2008 \\
\hline \#6 & Qinghai Province Tibetan Medicine Hospital, Xining, Qinghai, China & Processed in August 2010 \\
\hline$\# 7$ & Qinghai Province Tibetan Medicine Hospital, Xining, Qinghai, China & Processed in September 2009 \\
\hline$\# 8$ & Qinghai Province Tibetan Medicine Hospital, Xining, Qinghai, China & Processed in September 2008 \\
\hline \#9 & $\begin{array}{c}\text { The Company of Tibetan Medicine of Tibetan Autonomous Region, Lhasa, } \\
\text { Tibet, China }\end{array}$ & Collected on January 8, 2010 \\
\hline
\end{tabular}

As known, heavy metals could pose potentially serious hazard to human health. So, the biological safety and efficacy of Zuotai containing mercury need urgently to be reevaluated from a modern medical science perspective. Surprisingly, its toxicity tests suggest that Zuotai has no apparently adverse effects on animal subjects under clinical equivalent dose and clinical medication cycle [11, 13-16]. Besides, pharmacological experiments show that Zuotai not only can tranquilize and allay excitement, promote sleep, and produce antipyretic effect $[17,18]$, but also can enhance immunity, have antiinflammatory effects, extend the life of fruit flies, and inhibit the expression of caspase-3, along with other effects [18-21]. It is confusing why this Tibetan drug containing mercury shows tiny/nontoxicity and various efficacies in animal tests. Biological effects of heavy metals not only relate to doses, but also have closer relationship with their chemical forms; for example, $\mathrm{Cr}^{+3}$ is an essential element for mammals with a role in maintaining proper carbohydrate and lipid metabolism; on the contrary, $\mathrm{Cr}^{+6}$ has carcinogenic toxicity and genotoxicity [22-25]. So, it is crucial to reveal the chemical species of heavy metals in Zuotai for elucidating its pharmacological functions and mechanisms.

Until now, only a few literatures about physicochemical characterization of Zuotai are available. Yan [26, 27], Lan et al. [28], and Zhao et al. [29] reported that Zuotai was mainly an inorganic mixture of $\mathrm{HgS}$, sulfur, graphite, and other tiny organic molecules, and it was composed of nanoparticles, which further aggregated into microsized particles. However, there still lacks more information about the chemical structure, micromorphology, and XRD fingerprint features of Zuotai from large sample sizes. Therefore, in the present research, nine Zuotai samples were collected from four major Tibetan regions (Tibet, Qinghai, Gansu, and Sichuan) in China. The element compositions, phase structures, and micromorphology of these samples are analyzed by energy dispersive spectrometry of X-ray (EDX), powder X-ray diffraction (XRD), scanning electron microscopy (SEM), and atomic force microscopy (AFM), respectively. Additionally, the powder XRD fingerprint features of Zuotai were analyzed by applying multivariate statistical analysis methods (similarity calculation, systemic cluster analysis, and principal component analysis).

\section{Materials and Methods}

2.1. Materials. Nine Zuotai samples were kindly provided from the four Tibetan medicine organizations of four major Tibetan regions in China, respectively. The sources of Zuotai samples were listed in Table 1 . The main technology that processes these samples was well recorded and protected by the patent (number 88107006.8) in China [8]. Before characterization, these samples were sealed in glass bottles and covered by blue cloths according to their traditional storage method.

2.2. Measurement of Physicochemical Characteristics. The elements in nine Zuotai samples were detected by energy dispersive spectrometry of X-ray (EDX, INCA, Oxford Instruments, Inc.). EDX is a kind of semiquantitative elemental analysis method. The working conditions of EDX are operating voltage of $20 \mathrm{kV}$, beam spot size of $55 \mathrm{~nm}$, working distance of $8 \mathrm{~mm}$, and hit rates of $2500 \mathrm{cps}$.

The phase compositions of samples were characterized by powder X-ray diffraction (XRD, X'Pert Pro, PANalytical Company). The working conditions of XRD are $\mathrm{Cu}$ target, wavelength of $0.15406 \mathrm{~nm}, \mathrm{~K}(\alpha 1)$ energy of $40 \mathrm{keV}$, current intensity of $30 \mathrm{~mA}$, scanning speed of $2^{\circ} / \mathrm{min}$, and $2 \theta$ angle scan range of $5^{\circ}-80^{\circ}$. Powder $\mathrm{X}$-ray diffraction data were acquired by X'Pert Data Collector and analyzed by X'Pert HighScore Plus using PDF2-2004 of the International Centre for Diffraction Data. Powder XRD spectra were drawn by Origin 8.0. The crystal structure graphs of phase compositions in Zuotai were acquired by Diamond 3.2 and FindIt 2009.

The micromorphologies of Zuotai were measured by scanning electron microscopy (SEM, JSM-5610LV, Japanese Electronics Co., Ltd.) and atomic force microscopy (AFM, 
TABLE 2: Elemental contents in nine Zuotai samples by energy dispersive spectrometry of X-ray (EDX).

\begin{tabular}{|c|c|c|c|c|c|c|c|}
\hline Samples & Items & $\mathrm{O}$ & $\mathrm{Al}$ & S & $\mathrm{Fe}$ & $\mathrm{Cu}$ & $\mathrm{Hg}$ \\
\hline \multirow{2}{*}{$\# 1$} & Weight \% & 6.36 & 0.42 & 23.06 & 0.62 & 0.83 & 68.72 \\
\hline & Atomic \% & 26.52 & 1.04 & 47.98 & 0.74 & 0.87 & 22.86 \\
\hline \multirow{2}{*}{$\# 2$} & Weight \% & 6.44 & - & 38.98 & 0.67 & - & 53.92 \\
\hline & Atomic \% & 21.19 & - & 64.03 & 0.63 & - & 14.16 \\
\hline \multirow{2}{*}{ \#3 } & Weight \% & 4.06 & - & 32.44 & - & - & 63.5 \\
\hline & Atomic \% & 16.03 & - & 63.96 & - & - & 20.01 \\
\hline \multirow{2}{*}{$\# 4$} & Weight \% & 3.01 & - & 31.89 & - & - & 65.1 \\
\hline & Atomic \% & 12.5 & - & 65.97 & - & - & 21.53 \\
\hline \multirow{2}{*}{$\# 5$} & Weight \% & 3.71 & - & 31.11 & - & - & 65.18 \\
\hline & Atomic \% & 15.18 & - & 63.54 & - & - & 21.28 \\
\hline \multirow{2}{*}{ \#6 } & Weight \% & 4.09 & - & 20.14 & 0.53 & - & 75.24 \\
\hline & Atomic \% & 20.16 & - & 49.52 & 0.75 & - & 29.58 \\
\hline \multirow{2}{*}{ \#7 } & Weight \% & 3.36 & - & 20.8 & 0.71 & - & 75.12 \\
\hline & Atomic \% & 16.87 & - & 52.06 & 1.02 & - & 30.05 \\
\hline \multirow{2}{*}{$\# 8$} & Weight \% & 3.22 & - & 22.57 & 0.6 & - & 73.61 \\
\hline & Atomic \% & 15.67 & - & 54.88 & 0.84 & - & 28.61 \\
\hline \multirow{2}{*}{$\# 9$} & Weight \% & 2.76 & - & 22.52 & 0.66 & - & 74.06 \\
\hline & Atomic \% & 13.75 & - & 55.91 & 0.94 & - & 29.39 \\
\hline
\end{tabular}

Note: \#1 is the sample of Aba Prefecture Tibetan Medicine Hospital; \#2 is the sample of Gan'na Prefecture Tibetan Medicine Hospital; \#3, \#4, and \#5 are the samples of the Company of Tibetan Medicine of Tibetan Traditional Medical College; \#6, \#7, and \#8 are the samples of Qinghai Province Tibetan Medicine Hospital; \#9 is the sample of the Company of Tibetan Medicine of Tibetan Autonomous Region.

Bioscope Resolve, Bruker Corporation). The working conditions of SEM are LV mode, acceleration voltage of $30 \mathrm{kV}$, working distance of $8 \mathrm{~mm}$, and working pressure of $1 \mathrm{MPa}$ in electron gun chamber. The working conditions of AFM are ScanAsyst Auto Control, RTESPA-300 probe, scan size of $1 \mu \mathrm{m}$, scan rate of $1 \mathrm{~Hz}$, sample/line of 256 , peak force amplitude of $150 \mathrm{~nm}$, and $Z$ range of $17.9 \mu \mathrm{m}$.

2.3. Analysis of Powder XRD Fingerprint. The powder XRD fingerprint features were studied with multivariate statistical analysis methods (similarity calculation, systemic cluster analysis, and principal component analysis) by SPSS 22.0 statistical analysis software.

\section{Results}

3.1. Elemental Compositions of Zuotai. A large amount of mercury ( $\mathrm{Hg})$, sulfur (S), and oxygen (O) was found in nine Zuotai samples by EDX analysis. Besides, a small amount of other elements has also been found, such as ferrum $(\mathrm{Fe})$, aluminum $(\mathrm{Al})$, and cuprum $(\mathrm{Cu})$. The results are shown in Table 2 and Supplementary Figure 1 (in Supplementary Material available online at http://dx.doi.org/10.1155/2016/7010519). However, we should note that the oxygen $(\mathrm{O})$ in Zuotai may be interfered with inevitably to a certain extent by the residual oxygen from air in the sample testing chamber of EDX. So, whether Zuotai samples contain such high level oxygen element needs further study.
3.2. Micromorphology of Zuotai. Nine Zuotai samples display a variety of micromorphologies, which are composed of a large number of irregular nano-microparticles by scanning electron microscopy (SEM) and atomic force microscopy (AFM), as shown in Figures 1 and 2, respectively. The diameters of these particles vary mostly in the range of $100-800 \mathrm{~nm}$, some even less than $100 \mathrm{~nm}$. And these nanomicroparticles commonly further aggregate into $1-30 \mu \mathrm{m}$ loosely amorphous particles. There are a number of literature reports in both the basic science and pharmaceutics which scientifically define dimensions of nanoparticles ranging in size from 1 to $1000 \mathrm{~nm}$ [30-34]. According to this, Zuotai should be a kind of ancient nanodrug in traditional Tibetan medicine.

3.3. Phase Compositions of Zuotai. Powder XRD analysis found that the common major phase compositions are cubic crystal mercuric sulfide $(\beta-\mathrm{HgS})$ and orthorhombic crystal elemental sulfur $\left(\mathrm{S}_{8}\right)$ in nine Zuotai samples (Figure 3, Table 3, and Figure 4). The spacing group of $\beta-\mathrm{HgS}$ in Zuotai is F$43 \mathrm{~m}$ (216) with cell parameters $a=b=c=5.8580$ and $\alpha=\beta=\gamma=90^{\circ}$. The spacing group of $\mathrm{S}_{8}$ in nine samples is Fddd (70): $a=10.4646, b=12.8660, c=24.4860$, and $\alpha=\beta=\gamma=90^{\circ}$. Additionally, except for \#9 sample, all the other samples contain a small amount of hexagonal crystal mercuric sulfide ( $\alpha$-HgS) (Figures 3 and 4 and Table 3 ). The spacing group of $\alpha$-HgS in the samples from \#1 to \#8 is P3221 (154) with cell parameters $a=b=4.1495, c=9.4970$, and $\alpha=\beta=90^{\circ}, \gamma=120^{\circ}$. Besides, there are also many unknown weak diffraction signals in the nine samples. 


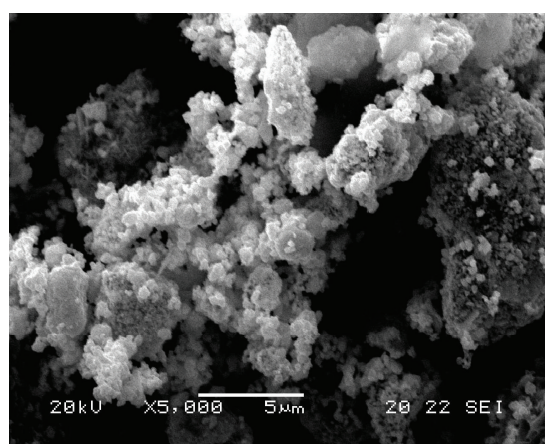

$\# 1$

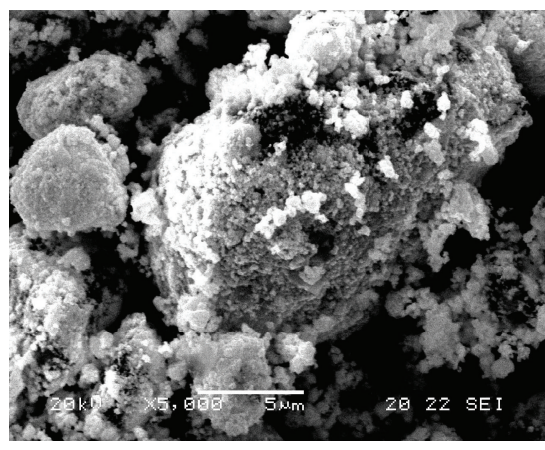

\#4

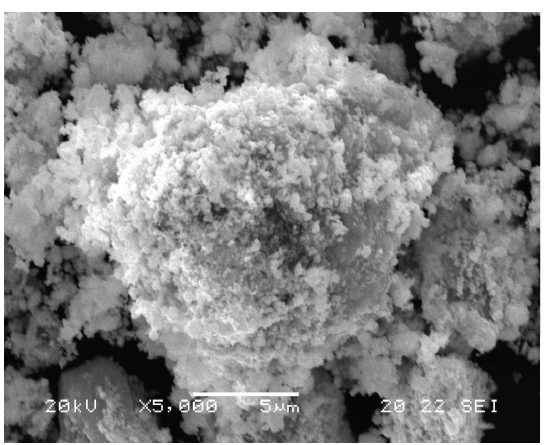

\#7

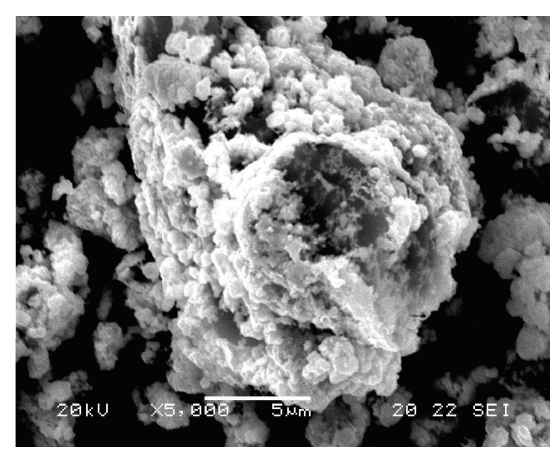

\#2

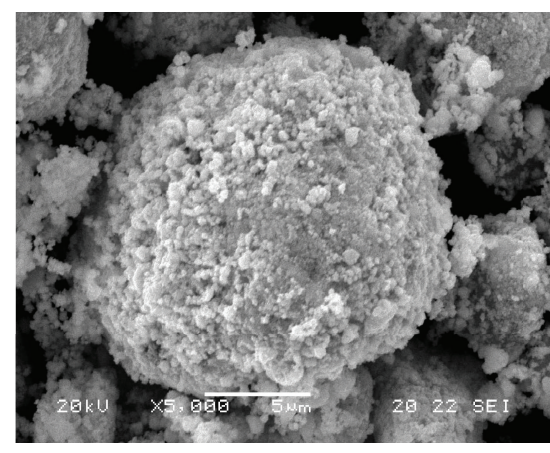

\#5

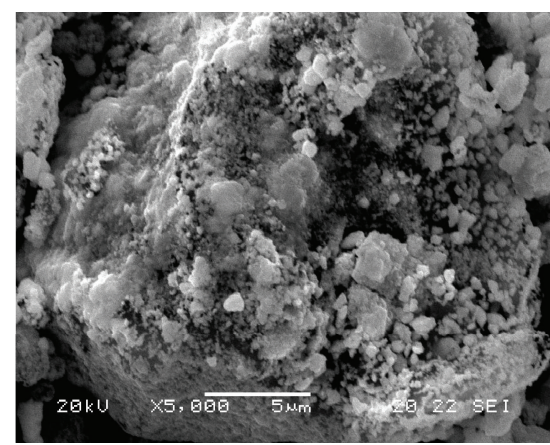

\#8

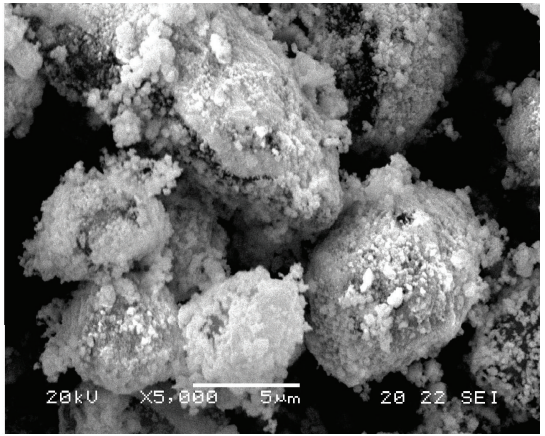

\#3

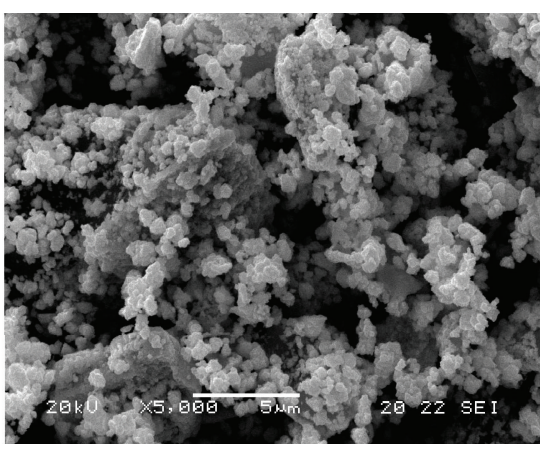

\#6

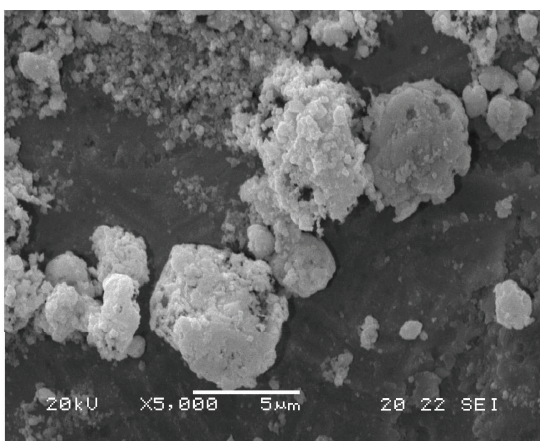

\#9

FIGURE 1: Micron size morphologies of nine Zuotai samples by scanning electron microscopy (SEM). Note: \#1 is the sample of Aba Prefecture Tibetan Medicine Hospital; \#2 is the sample of Gan'na Prefecture Tibetan Medicine Hospital; \#3, \#4, and \#5 are the samples of the Company of Tibetan Medicine of Tibetan Traditional Medical College; \#6, \#7, and \#8 are the samples of Qinghai Province Tibetan Medicine Hospital; \#9 is the sample of the Company of Tibetan Medicine of Tibetan Autonomous Region.

This result indicates that the chemical species of mercury in Zuotai are cubic crystal mercuric sulfide $(\beta-\mathrm{HgS})$ and hexagonal mercuric sulfide $(\alpha-\mathrm{HgS})$ without elemental mercury. Both mercuric sulfides are typical covalent insoluble sulfides. The solubility product constant of $\beta$ - $\mathrm{HgS}$ is $1.6 \times$ $10^{-52}$; the solubility product constant of $\alpha$ - $\mathrm{HgS}$ is $4.0 \times 10^{-53}$ [35]. So far, there is no definitive evidence showing that the two chemical forms of mercury are toxic in the human body $[36,37]$.

\subsection{Powder XRD Fingerprint Analysis of Zuotai}

3.4.1. Establishing XRD Fingerprint. The means of diffraction intensity at different $2 \theta$ angles were acquired by overlaying the diffraction topology spectra of nine samples firstly and then averaging. According to these means, the powder XRD fingerprint (average) of Zuotai was drawn by Origin 8.0 (Figure 5). Besides, according to the medians of diffraction intensity of nine samples at different $2 \theta$ angles, the powder XRD fingerprint (median) was also drawn by Origin 8.0 (Figure 6).

3.4.2. Similarity Calculation of Nine Zuotai Samples. The XRD fingerprints (average and median) of Zuotai were considered as controls; the similarity degrees (cosine and correlation coefficient) of nine Zuotai samples were calculated with SPSS 22.0. The results show that the similarity degrees of the nine samples are very high (all cosines and correlation coefficients $>0.9950$ ) in Table 4 . 

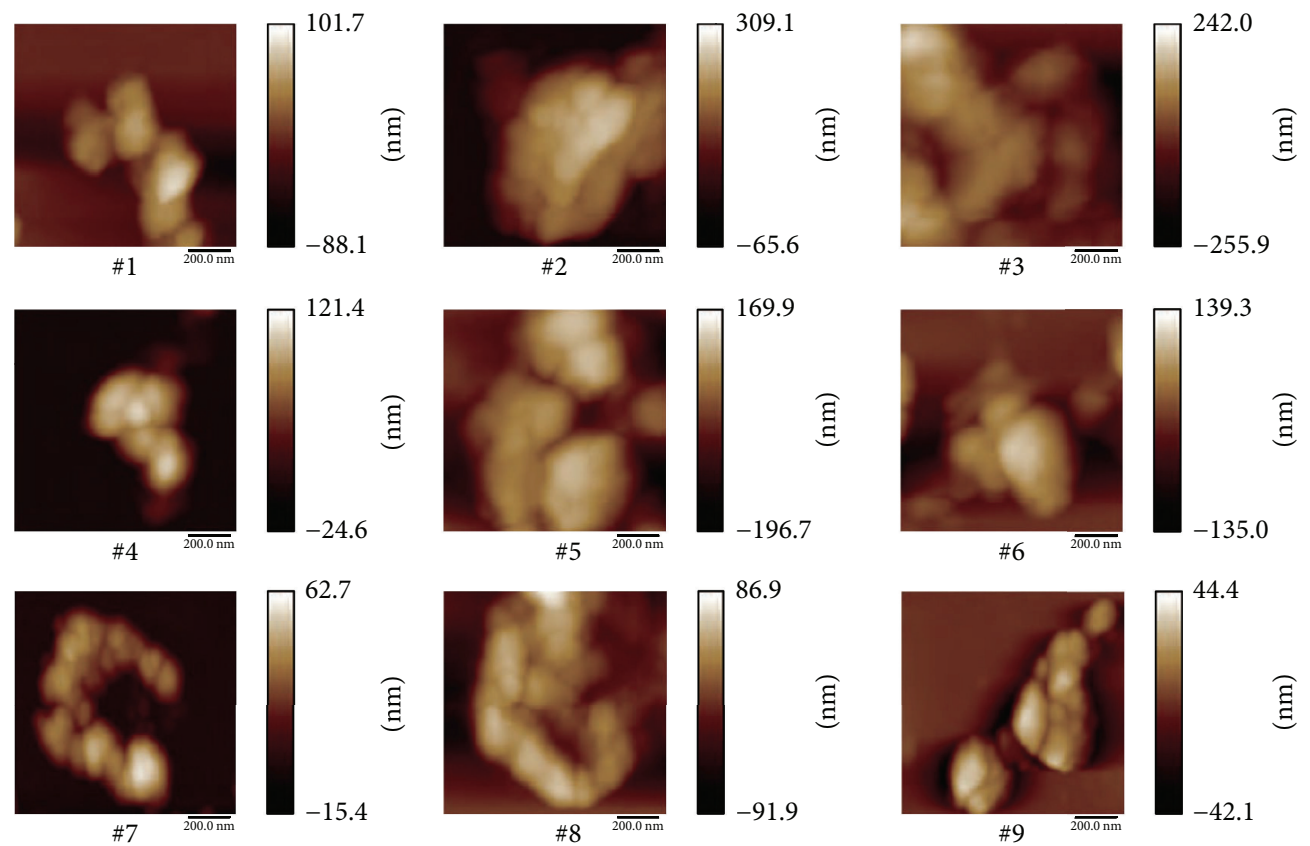

Figure 2: Nanometer size morphologies of nine Zuotai samples by atomic force microscopy (AFM). Note: \#1 is the sample of Aba Prefecture Tibetan Medicine Hospital; \#2 is the sample of Gan'na Prefecture Tibetan Medicine Hospital; \#3, \#4, and \#5 are the samples of the Company of Tibetan Medicine of Tibetan Traditional Medical College; \#6, \#7, and \#8 are the samples of Qinghai Province Tibetan Medicine Hospital; \#9 is the sample of the Company of Tibetan Medicine of Tibetan Autonomous Region.

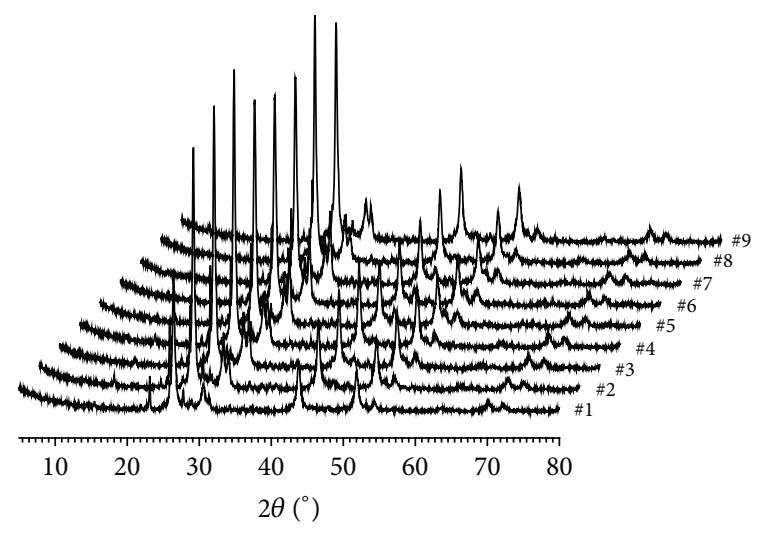

FIgure 3: Powder XRD spectrum of nine Zuotai samples. Note: $\# 1$ is the sample of Aba Prefecture Tibetan Medicine Hospital; \#2 is the sample of Gan'na Prefecture Tibetan Medicine Hospital; \#3, $\# 4$, and \#5 are the samples of the Company of Tibetan Medicine of Tibetan Traditional Medical College; \#6, \#7, and \#8 are the samples of Qinghai Province Tibetan Medicine Hospital; \#9 is the sample of the Company of Tibetan Medicine of Tibetan Autonomous Region.

3.4.3. Cluster Analysis of Nine Zuotai Samples. 25 common peaks (Supplementary Table 1) are found through analyzing all the diffraction peaks of nine samples in Jade 5.0. And the relative intensities $\left(I / I_{0}\right)$ of 25 common characteristic peaks were considered as indicators; nine Zuotai samples were clustered with systematic cluster analysis [38-40] by SPSS 22.0. According to the characteristics of X-ray diffraction analysis data, the between-groups linkage method $\left(D_{k l}=\right.$ $\left.\left(1 / n_{k} n_{l}\right) \sum_{x_{i} \in G_{k}} \sum_{x_{i} \in G_{l}} d_{i j}\right)$ is used to measure the distance between both groups; the Mahalanobis distance method $\left(d_{i j}=\left(x_{i}-x_{j}\right)^{\prime} S^{-1}\left(x_{i}-x_{j}\right)\right)$ is applied to measure the distance between samples, in which $n$ refers to sample number, $n_{k}$ and $n_{l}$ refer to the $k$ th sample and the $l$ th sample, $G_{k}$ and $G_{l}$ refer to the $k$ th group and the $l$ th group, $D_{k l}$ refers to the distance between group $G_{k}$ and group $G_{l}, d_{i j}$ refers to the distance between sample $x_{i}$ and sample $x_{j}$, and $S^{-1}$ refers to the inverse matrix of sample covariance matrix. The result of cluster analysis is shown in Figure 7.

When the relative distance is 10 , nine samples are clustered in four groups: \#3, \#4, and \#5 samples clustering together, \#1, \#6, and \#8 samples clustering together, \#2 and \#7 samples clustering together, and \#9 sample as a group alone. When relative distance is 23 , nine samples are clustered in two

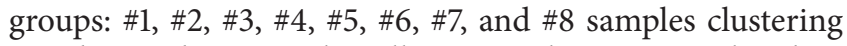
together and \#9 sample still as a single group. Only when relative distance is 25 can all of the samples be clustered together. This result is consistent with the phase composition differences of nine Zuotai samples. The samples from \#1 to \#8 contain cubic mercuric sulfide $(\beta-\mathrm{HgS})$, orthorhombic elemental sulfur $\left(\mathrm{S}_{8}\right)$, and hexagonal mercuric sulfide $(\alpha$ $\mathrm{HgS}$ ). But \#9 sample only contains cubic mercuric sulfide and orthorhombic sulfur, but not hexagonal mercuric sulfide.

3.4.4. Principal Component Analysis (PCA). Principal component analysis (PCA) is a kind of reducing dimensions method, in that data are projectedfrom high-dimensional 
TABLE 3: Phase compositions in nine Zuotai samples by powder XRD.

\begin{tabular}{|c|c|c|c|c|c|}
\hline Samples & ICDD & Compound & Chem. form. & Crystal system & Space group \\
\hline \multirow{3}{*}{$\# 1$} & 01-075-1538 & Metacinnabar & $\mathrm{HgS}$ & Cubic & F-43m (216) \\
\hline & 01-078-1889 & Sulfur, alpha & $\mathrm{S}_{8}$ & Orthorhombic & Fddd (70) \\
\hline & 00-042-1408 & Vermilion & $\mathrm{HgS}$ & Hexagonal & P3221 (154) \\
\hline \multirow{3}{*}{$\# 2$} & 01-075-1538 & Metacinnabar & $\mathrm{HgS}$ & Cubic & F-43m (216) \\
\hline & 01-078-1889 & Sulfur, alpha & $\mathrm{S}_{8}$ & Orthorhombic & Fddd (70) \\
\hline & 00-042-1408 & Vermilion & $\mathrm{HgS}$ & Hexagonal & P3221 (154) \\
\hline \multirow{3}{*}{ \#3 } & 01-075-1538 & Metacinnabar & $\mathrm{HgS}$ & Cubic & F-43m (216) \\
\hline & 01-078-1889 & Sulfur, alpha & $\mathrm{S}_{8}$ & Orthorhombic & Fddd (70) \\
\hline & 00-042-1408 & Vermilion & $\mathrm{HgS}$ & Hexagonal & P3221 (154) \\
\hline \multirow{3}{*}{$\# 4$} & 01-075-1538 & Metacinnabar & $\mathrm{HgS}$ & Cubic & F-43m (216) \\
\hline & 01-078-1889 & Sulfur, alpha & $\mathrm{S}_{8}$ & Orthorhombic & Fddd (70) \\
\hline & 00-042-1408 & Vermilion & $\mathrm{HgS}$ & Hexagonal & P3221 (154) \\
\hline \multirow{3}{*}{ \#5 } & 01-075-1538 & Metacinnabar & $\mathrm{HgS}$ & Cubic & F-43m (216) \\
\hline & 01-078-1889 & Sulfur, alpha & $\mathrm{S}_{8}$ & Orthorhombic & Fddd (70) \\
\hline & 00-042-1408 & Vermilion & $\mathrm{HgS}$ & Hexagonal & P3221 (154) \\
\hline \multirow{3}{*}{ \#6 } & 01-075-1538 & Metacinnabar & $\mathrm{HgS}$ & Cubic & F-43m (216) \\
\hline & 01-078-1889 & Sulfur, alpha & $\mathrm{S}_{8}$ & Orthorhombic & Fddd (70) \\
\hline & 00-042-1408 & Vermilion & $\mathrm{HgS}$ & Hexagonal & P3221 (154) \\
\hline \multirow{3}{*}{ \#7 } & 01-075-1538 & Metacinnabar & $\mathrm{HgS}$ & Cubic & F-43m (216) \\
\hline & 01-078-1889 & Sulfur, alpha & $\mathrm{S}_{8}$ & Orthorhombic & Fddd (70) \\
\hline & 00-042-1408 & Vermilion & $\mathrm{HgS}$ & Hexagonal & P3221 (154) \\
\hline \multirow{3}{*}{$\# 8$} & 01-075-1538 & Metacinnabar & $\mathrm{HgS}$ & Cubic & F-43m (216) \\
\hline & 01-078-1889 & Sulfur, alpha & $\mathrm{S}_{8}$ & Orthorhombic & Fddd (70) \\
\hline & 00-042-1408 & Vermilion & $\mathrm{HgS}$ & Hexagonal & P3221 (154) \\
\hline \multirow{2}{*}{$\# 9$} & 01-075-1538 & Metacinnabar & $\mathrm{HgS}$ & Cubic & F-43m (216) \\
\hline & 01-078-1889 & Sulfur, alpha & $\mathrm{S}_{8}$ & Orthorhombic & Fddd (70) \\
\hline
\end{tabular}

Note: \#1 is the sample of Aba Prefecture Tibetan Medicine Hospital; \#2 is the sample of Gan'na Prefecture Tibetan Medicine Hospital; \#3, \#4, and \#5 are the samples of the Company of Tibetan Medicine of Tibetan Traditional Medical College; \#6, \#7, and \#8 are the samples of Qinghai Province Tibetan Medicine Hospital; \#9 is the sample of the Company of Tibetan Medicine of Tibetan Autonomous Region.

TABLE 4: The similarity of XRD fingerprints of nine Zuotai samples.

\begin{tabular}{lcccc}
\hline \multirow{2}{*}{ Samples } & \multicolumn{2}{c}{ Average } & \multicolumn{2}{c}{ Median } \\
& Cosine & Correlation & Cosine & Correlation \\
\hline$\# 1$ & 0.9991 & 0.9988 & 0.9989 & 0.9986 \\
$\# 2$ & 0.9980 & 0.9980 & 0.9978 & 0.9976 \\
$\# 3$ & 0.9988 & 0.9985 & 0.9979 & 0.9974 \\
$\# 4$ & 0.9982 & 0.9980 & 0.9975 & 0.9974 \\
$\# 5$ & 0.9986 & 0.9983 & 0.9981 & 0.9978 \\
$\# 6$ & 0.9989 & 0.9987 & 0.9994 & 0.9993 \\
$\# 7$ & 0.9983 & 0.9984 & 0.9980 & 0.9979 \\
$\# 8$ & 0.9990 & 0.9986 & 0.9994 & 0.9993 \\
$\# 9$ & 0.9974 & 0.9968 & 0.9966 & 0.9958 \\
\hline
\end{tabular}

Note: \#1 is the sample of Aba Prefecture Tibetan Medicine Hospital; \#2 is the sample of Gan'na Prefecture Tibetan Medicine Hospital; \#3, \#4, and \#5 are the samples of the Company of Tibetan Medicine of Tibetan Traditional Medical College; \#6, \#7, and \#8 are the samples of Qinghai Province Tibetan Medicine Hospital; \#9 is the sample of the Company of Tibetan Medicine of Tibetan Autonomous Region.

space onto low-dimensional space, namely, using a smaller number of new variables instead of a huge number of original variables with minimal information loss [38-41]. In the process of PCA, the absolute intensity of X-ray diffraction can be used. The absolute intensities (I) of 25 common peaks of nine Zuotai samples were analyzed with PCA by SPSS 22.0, and then the initial eigenvalues (Table 5) and load matrix (Supplementary Table 2) of principal components are acquired.

In Table 5, the initial eigenvalues of the first three principal components are all greater than 2 , and the cumulative contribution rate of variance is $83.35(>80 \%)$. Therefore, the first three components (denoted as F1, F2, and F3, resp.) can well explain the inherent information of the original 25 characteristic peaks of nine Zuotai samples.

And the variables coefficients of principal component linear equation, namely, standardized eigenvector, can be calculated from the load values of principal components. The standardized eigenvector equation of principal components is $\widehat{t}_{i j}^{*}=r_{i j} / \sqrt{\widehat{\lambda}_{j}^{*}}$, in which $r_{i j}$ refers to the load of principal component, $\hat{\lambda}_{j}^{*}$ refers to initial eigenvalues, and $\widehat{t}_{i j}^{*}$ refers to standardized eigenvector $(i=1,2, \ldots, n ; j=$ $1,2, \ldots, p ; n$ is sample number; $p$ is the indicator number 


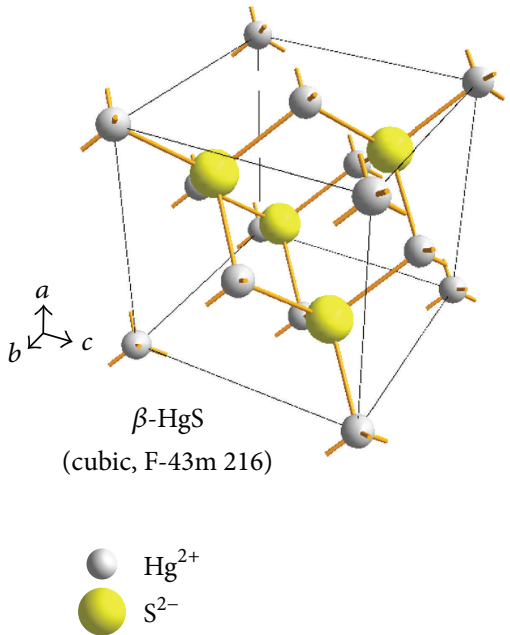

(a)

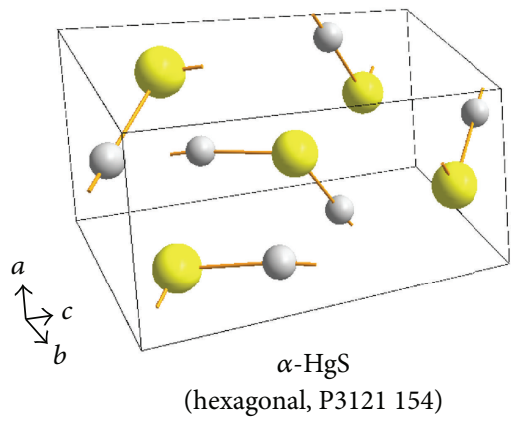

C $\mathrm{Hg}^{2+}$

(b)

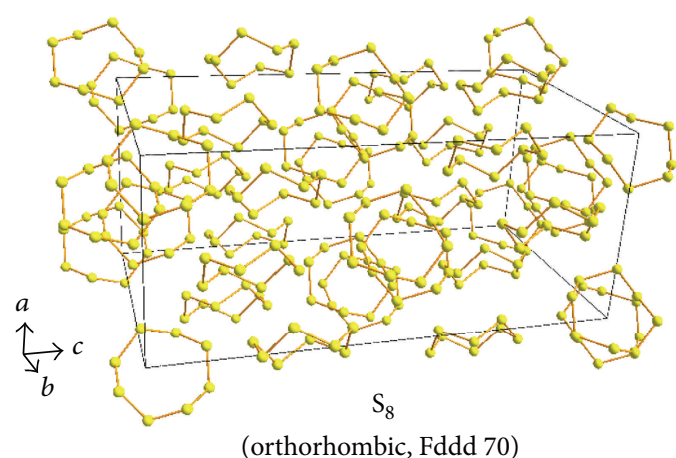

$S^{2-}$

(c)

Figure 4: Structures of phase compositions in Zuotai samples. Note: (a), (b), and (c) are the crystal structures of $\beta$-HgS, $\alpha$-HgS, and $\mathrm{S}_{8}$, respectively.

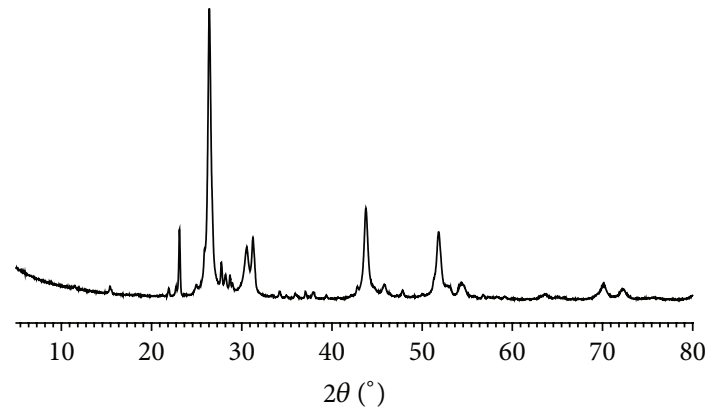

FIGURE 5: XRD fingerprint of Zuotai (average).

of sample). According to this equation, standardized eigenvectors (shown in Supplementary Table 3) of the first three principal components $(F 1, F 2$, and $F 3)$ are calculated. The linear equations of the first three principal components ( $F 1$, $F 2$, and F3) are obtained through multiplying the standardized eigenvectors with the corresponding normalized peak

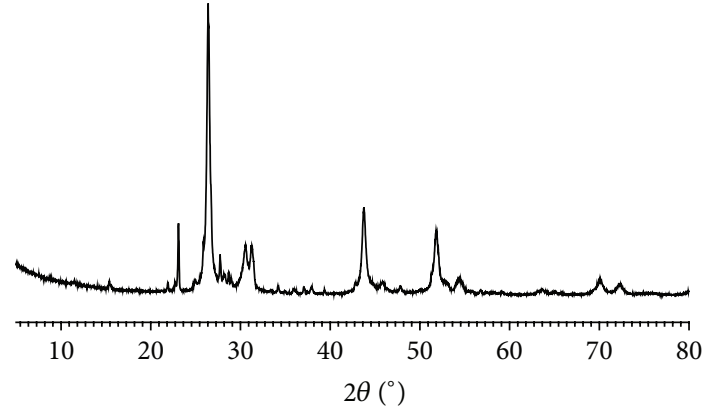

FIGURE 6: XRD fingerprint of Zuotai (median).

intensity $(Z X)$. The equations of $F 1, F 2$, and $F 3$ of Zuotai are as follows:

$$
\begin{aligned}
F 1= & 0.1130 Z X_{1}+0.2376 Z X_{2}+0.2437 Z X_{3} \\
& +0.2701 Z X_{4}+0.2544 Z X_{5}+0.1813 Z X_{6} \\
& +0.2470 Z X_{7}+0.1665 Z X_{8}+0.0091 Z X_{9}
\end{aligned}
$$




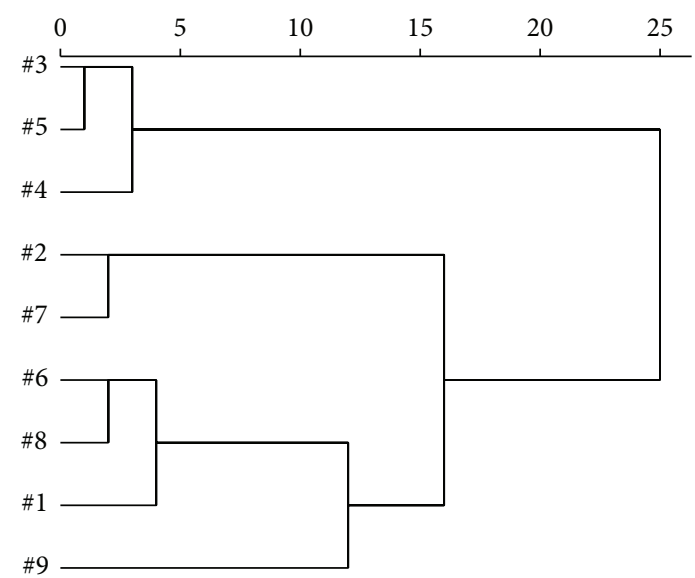

FIgURE 7: The cluster analysis result of nine Zuotai samples. Note: $\# 1$ is the sample of Aba Prefecture Tibetan Medicine Hospital; \#2 is the sample of Gan'na Prefecture Tibetan Medicine Hospital; \#3, $\# 4$, and \#5 are the samples of the Company of Tibetan Medicine of Tibetan Traditional Medical College; \#6, \#7, and \#8 are the samples of Qinghai Province Tibetan Medicine Hospital; \#9 is the sample of the Company of Tibetan Medicine of Tibetan Autonomous Region.

TABLE 5: Initial eigenvalues of principal components.

\begin{tabular}{|c|c|c|c|}
\hline \multirow{2}{*}{ Component } & \multicolumn{3}{|c|}{ Initial eigenvalues } \\
\hline & Total & $\%$ of variance & Cumulative \% \\
\hline 1 & 13.16 & 52.641 & 52.641 \\
\hline 2 & 4.843 & 19.372 & 72.013 \\
\hline 3 & 2.834 & 11.337 & 83.35 \\
\hline 4 & 1.631 & 6.522 & 89.872 \\
\hline 5 & 1.074 & 4.296 & 94.168 \\
\hline 6 & 0.669 & 2.677 & 96.845 \\
\hline 7 & 0.571 & 2.284 & 99.128 \\
\hline$\vdots$ & $\vdots$ & $\vdots$ & $\vdots$ \\
\hline 25 & $-6.03 E-16$ & $-2.41 E-15$ & 100 \\
\hline
\end{tabular}

$$
\begin{aligned}
& +0.2409 Z X_{10}+0.1852 Z X_{11}+0.2034 Z X_{12} \\
& +0.0309 Z X_{13}+0.2390 Z X_{14}+0.2280 Z X_{15} \\
& +0.1753 Z X_{16}+0.0549 Z X_{17}+0.2575 Z X_{18} \\
& +0.1298 Z X_{19}+0.2415 Z X_{20}+0.1513 Z X_{21} \\
& +0.1935 Z X_{22}+0.1615 Z X_{23}+0.2558 Z X_{24} \\
& +0.2018 Z X_{25}, \\
F 2= & 0.3458 Z X_{1}-0.1618 Z X_{2}-0.0704 Z X_{3} \\
& -0.0141 Z X_{4}+0.1313 Z X_{5}+0.1977 Z X_{6} \\
& +0.1077 Z X_{7}+0.1423 Z X_{8}-0.3617 Z X_{9} \\
& -0.1709 Z X_{10}+0.2935 Z X_{11}+0.2395 Z X_{12} \\
& +0.2536 Z X_{13}-0.1322 Z X_{14}+0.0136 Z X_{15}
\end{aligned}
$$

$$
\begin{aligned}
& -0.2367 Z X_{16}+0.1868 Z X_{17}+0.0545 Z X_{18} \\
& -0.2245 Z X_{19}+0.0573 Z X_{20}-0.2254 Z X_{21} \\
& -0.2527 Z X_{22}+0.2267 Z X_{23}-0.0341 Z X_{24} \\
& -0.2461 Z X_{25}, \\
F 3= & 0.1907 Z X_{1}-0.0190 Z X_{2}-0.0160 Z X_{3} \\
& +0.0731 Z X_{4}-0.0178 Z X_{5}+0.2727 Z X_{6} \\
& +0.0594 Z X_{7}+0.3261 Z X_{8}+0.2964 Z X_{9} \\
& +0.0006 Z X_{10}+0.0386 Z X_{11}-0.1960 Z X_{12} \\
& +0.2032 Z X_{13}-0.1230 Z X_{14}+0.1622 Z X_{15} \\
& +0.3024 Z X_{16}+0.3095 Z X_{17}-0.1687 Z X_{18} \\
& -0.3024 Z X_{19}-0.2014 Z X_{20}+0.3297 Z X_{21} \\
& -0.0422 Z X_{22}-0.3047 Z X_{23}-0.1028 Z X_{24} \\
& -0.0321 Z X_{25} .
\end{aligned}
$$

According to the above linear equations of Zuotai, the principal component scores of nine Zuotai samples were calculated, and the 3D space scatter diagram (Figure 8) of these samples is drawn by SPSS 22.0.

The PCA result shows that nine Zuotai samples can be classed into three groups: \#1, \#2, \#6, \#7, and \#8 are clustered together; \#3, \#4, and \#5 samples are clustered together; \#9 sample is clustered as a single group. Moreover, the distance between the first two groups is closer than with the third group on $F 1$ coordinate axis. The result of PCA is consistent broadly with systemic cluster analysis.

\section{Discussion}

Tibetan medicine has been playing an important role in the health, reproduction, and development of Tibetan people. Zuotai is the key raw material of many precious compound preparations in Tibetan medicine, with tonic effects, reducing toxicity, increasing efficacy, replenishing blood, promoting blood flow, promoting tissue regeneration, invigorating the spleen, and prolonging one's life, among other effects [48]. Zuotai is the common name of "Renqing Ouqu Zuozhu Qinmu" in Tibetan medicine. "Zuo" means refining, burning, smelting, and cooking; "Tai" means ashes, powder, and gray powder; "Zuotai" means the powder of burning, burning into powder, and calcining mercury into ash $[4,11,19,20,26,27$, 42-44]. Therefore, Zuotai not only is the name of processing product, but also is the name of processing technology [4, $5,11]$. The technology of mercury refining into Zuotai was recorded in "Sibu Yidian" (Four Medical Codes), a Tibetan medicine classic, in the AC 8th century, and was improved by $\mathrm{U}$ rgyan pa Rin chen dpal, a famous Tibetan medicine practitioner, in AC 13th century [12, 45]. This technology has had profound influence on the sciences of Tibetan medicine processing, medical formulae, and life cultivation. Almost 


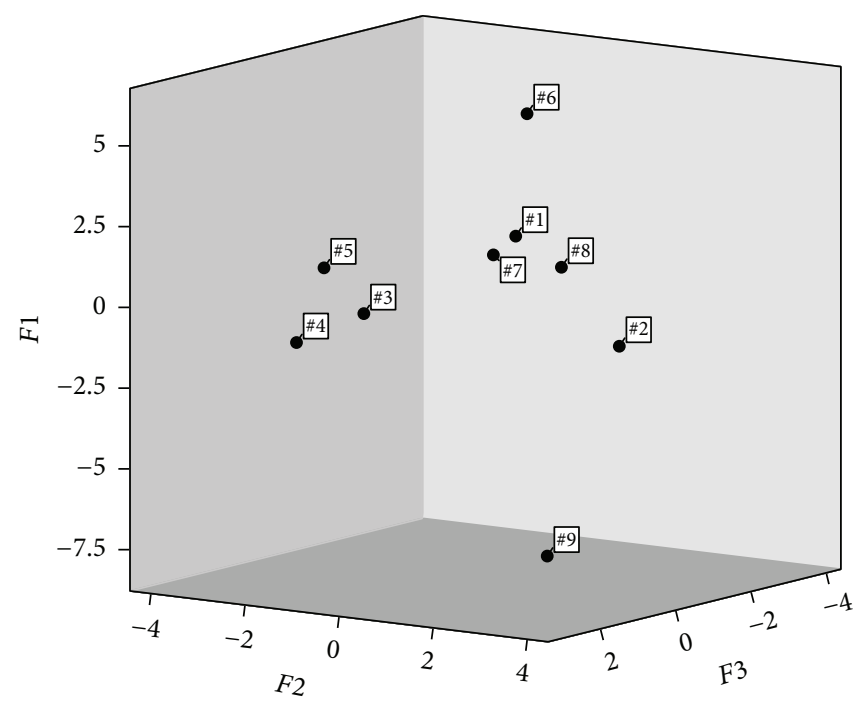

Figure 8: The PCA result of XRD fingerprint of nine Zuotai samples. Note: \#1 is the sample of Aba Prefecture Tibetan Medicine Hospital; \#2 is the sample of Gan'na Prefecture Tibetan Medicine Hospital; \#3, \#4, and \#5 are the samples of the Company of Tibetan Medicine of Tibetan Traditional Medical College; \#6, \#7, and \#8 are the samples of Qinghai Province Tibetan Medicine Hospital; \#9 is the sample of the Company of Tibetan Medicine of Tibetan Autonomous Region.

the alchemy of Chinese Taoist and the mercury praeparatum technology of Indian Tantra had already gone away with history, but only the processing technology of Zuotai survives and flourishes till today; this may have been because Zuotai has been used as a core adjuvant in many precious Tibetan medicine component preparations [45, 46]. Meanwhile, this conserves a kind of unique ancient technology for traditional Tibetan culture. In 2006, the processing technology of Zuotai has been collected in the Chinese Intangible Cultural Heritage List [47].

Nanometer is not only a concept of spatial scale, but also a new way of thinking. The present research found that Zuotai particles are mainly in $100-800 \mathrm{~nm}$ range, and some are less than $100 \mathrm{~nm}$, which commonly aggregate into about 1$30 \mu \mathrm{m}$ loosely amorphous particles. This is consistent with the reports of Yan et al. [26], Lan et al. [28], and Zhao et al. [29]. In the pharmaceutical field, the particle size of a nanodrug is generally defined in the range from $1 \mathrm{~nm}$ to $1000 \mathrm{~nm}$ [30-34]. So, this indicates that Zuotai is a kind of ancient nanodrug. There are three main absorption ways of oral nanoparticles in the intestinal tract [48, 49]: (1) paracellular passageparticles "kneading" between intestinal epithelial cells due to their extremely small size $(<50 \mathrm{~nm}) ;(2)$ endocytotic uptake - particles absorbed by intestinal enterocytes through endocytosis (particles size $<500 \mathrm{~nm}$ ); (3) lymphatic uptakeparticles adsorbed by $M$ cells of Peyer's patches (particle size $<5 \mu \mathrm{m}$ ). It is surprising to find that the scale of Zuotai particles coincides with modern nanodrug concept. This finding greatly arouses our interests in this ancient nanodrug. According to the above absorption ways of nanodrugs in the intestine, Zuotai particles may mainly be absorbed through the intestinal epithelial cells and the M cells of Peyer's patches.

Accurate characterization for the chemical species of heavy metals in Zuotai is the prerequisite of understanding its peculiarly biological effects. The present study suggests that Zuotai contains cubic $\alpha-\mathrm{HgS}(\mathrm{F}-43 \mathrm{~m}, 216)$, orthorhombic $\mathrm{S}_{8}$ (Fddd, 70), and hexagonal $\alpha$-HgS (P3221, 154). Besides, there are still many unknown very weak X-ray diffraction signals, which are difficult to analyze. According to the processing technology of Zuotai, we can know that it is obtained through mixing the burned Nengchi Eight Eshes and the burned Nengchi Eight Mineral Ashes into the prepared mercury powder at $3.3 \%$ rate, respectively. The chemical components of Nengchi Eight Eshes and Nengchi Eight Mineral Ashes have been reported [50, 51] by some authors of the present paper. The other phase compositions of Zuotai can be deduced from the Nengchi Eight Eshes and the refined Nengchi Eight Mineral Ashes. Therefore, except for the main phase compositions above, Zuotai also should contain minor or trace quadratic $\mathrm{AuPb}_{2}$ (I4/mcm, 144), quadratic $\mathrm{PbO}(\mathrm{P} 4 / \mathrm{nmm}, 129)$, orthorhombic $\mathrm{PbO}$ (Pbma, 57), cubic $\mathrm{Pb}$ (Fm-3m, 225), monoclinic $\mathrm{Ag}_{2} \mathrm{~S}$ (P21/n, 14), quadratic $\mathrm{Cu}_{1.98}\left(\mathrm{Zn}_{0.73} \mathrm{Fe}_{0.29}\right) \mathrm{Sn}_{0.99} \mathrm{~S}_{4}(\mathrm{I}-$ 4, 82), hexagonal $\mathrm{CuS}(\mathrm{P} 63 / \mathrm{mmc}, 194)$, hexagonal $\mathrm{SiO}_{2}$ (P3121, 152), hexagonal $\mathrm{NaCu}_{2} \mathrm{~S}_{2}(\mathrm{P} 3 \mathrm{ml}, 156)$, rhomboidal $\mathrm{Ca}\left(\mathrm{Fe}_{+2}, \mathrm{Mg}\right)\left(\mathrm{CO}_{3}\right)_{2}(\mathrm{R}-3,148)$, orthorhombic $\mathrm{Cu}_{7} \mathrm{~S}_{4}$ (Pnma, 62), monoclinic $\mathrm{Cu}_{7} \mathrm{~S}_{4}(\mathrm{C} 2 / \mathrm{m}, 12)$, monoclinic $\mathrm{CuO}(\mathrm{C} 2 / \mathrm{c}$, 15), hexagonal FeS (P-62c, 192), cubic PbS (Fm-3m, 226), cubic $\mathrm{ZnS}$ (F-43m, 216), rhomboidal $\mathrm{CaCO}_{3}$ (R-3c, 167), cubic $\mathrm{Fe}_{+2} \mathrm{Fe}_{2+3} \mathrm{O}_{4}$ (namely, $\mathrm{Fe}_{3} \mathrm{O}_{4} ; \mathrm{Fd}-3 \mathrm{~m}, 227$ ), orthorhombic SnS (Pnma, 62), orthorhombic $\mathrm{PbSO}_{4}$ (Pnma, 62), hexagonal $\mathrm{SnS}_{2}$ (P63mc, 186), cubic KCl (Fm-3m, 225), monoclinic $\mathrm{K}(\mathrm{Mg}, \mathrm{Fe})_{3}(\mathrm{Al}, \mathrm{Fe}) \mathrm{Si}_{3} \mathrm{O}_{10}(\mathrm{OH}, \mathrm{F})_{2}(\mathrm{C} 2 / \mathrm{m}, 12)$, orthorhombic $\mathrm{Mg}_{2} \mathrm{SiO}_{4}$ (Pbnm, 62), monoclinic $\mathrm{KMg}_{3} \mathrm{Si}_{3} \mathrm{AlO}_{10}(\mathrm{~F}, \mathrm{OH})_{2}$ $(\mathrm{C} 2 / \mathrm{m}, 12)$, triclinic $\left(\mathrm{Na}_{0.4} \mathrm{Ca}_{0.6}\right) \mathrm{Al}_{1.6} \mathrm{Si}_{2.4} \mathrm{O}_{8}$ (unknown spacing group), orthorhombic FeAs (Pnma, 62), monoclinic $\mathrm{K}_{2} \mathrm{Ca}\left(\mathrm{SO}_{4}\right)_{2} \cdot \mathrm{H}_{2} \mathrm{O}\left(\mathrm{P} 21 / \mathrm{m}, 11\right.$ ), orthorhombic $\mathrm{FeAs}_{2}$ (Pnnm, 58), quadratic $\mathrm{Fe}_{2}$ As (P4/nmm, 129), rhombic-hexahedral 
$\mathrm{CaCO}_{3}$ (R-3c, 167), cubic $\mathrm{Cu}_{2} \mathrm{~S}$ (Fm-3m, 225), and so on [45, 47]. Besides, Yan et al. [26, 27] and Lan et al. [28] reported that Zuotai may also contain some amount of $\mathrm{FeC}, \varepsilon-\mathrm{Fe}_{2} \mathrm{O}_{3}$, $\left(\mathrm{S}_{4} \mathrm{~N}_{3}\right) \mathrm{Cl}, \mathrm{C}$, and trace organics. As seen from the above, the chemical components and crystal structures of Zuotai are extremely complex, and this may be the substance basis of its peculiar curative effects.

In summary, the present research suggests that mercury $(\mathrm{Hg})$ and sulfur $(\mathrm{S})$ are the major elements, and ferrum $(\mathrm{Fe})$, aluminum $(\mathrm{Al})$, and cuprum $(\mathrm{Cu})$ are the minor metal elements in Zuotai. The chemical species of mercury in Zuotai are insoluble cubic mercuric sulfide $(\beta-\mathrm{HgS})$ and minor hexagonal mercuric sulfide $(\alpha-\mathrm{HgS})$. And orthorhombic sulfur $\left(\mathrm{S}_{8}\right)$ is also the main phase composition in Zuotai. Moreover, Zuotai is a kind of ancient nanodrug in traditional Tibetan medicine. Its particles are mainly in the range from $100 \mathrm{~nm}$ to $800 \mathrm{~nm}$ and further aggregate into 1-30 $\mu \mathrm{m}$ loosely amorphous particles. Besides, the intrinsic relationship among samples from different sources is revealed through multivariate statistical analysis, according to the established powder XRD fingerprint of Zuotai. As an important drug containing heavy metals in Tibetan medicine, Zuotai has many mysteries, which are worth exploring. Science always has its historical limitation, and if the knowledge of contemporary science cannot explain it, we cannot abandon it blindly, but it needs to be handed down, waiting for the science of the future to explain it.

\section{Competing Interests}

The authors declare that they have no competing interests.

\section{Acknowledgments}

This work was funded by "The Dawn of West China" 2014 Talent Training Program of the Chinese Academy of Sciences (Y529021211), the National Natural Science Foundation of China (81374063), and the Science Foundation for Young Scholars of Qinghai Province (2016-ZJ-919Q).

\section{References}

[1] Xiang-duo Li-xian-jia and B.-F. Luo, "New explore on the origin of Tibetan Medicine," China Journal of Medical History, vol. 32, no. 3, pp. 188-191, 2002.

[2] Zong-ke Yang-zheng-gang-bu, "The Tibetan medicine conditions in the times of Tibetan tribes-countries," Tibetan Studies, vol. 4, pp. 85-96, 1996.

[3] Y. Zhen, "The initial analysis on Tibetan medicine origin," Journal of Medicine \& Pharmacy of Chinese Minorities, vol. 7, no. 2, pp. 39-40, 2001.

[4] Lan-ke, "The simple discussion of Tibetan medicine Zuota," Journal of Medicine \& Pharmacy of Chinese Minorities, vol. 5, supplement, article 86, 1995.

[5] Suo-lang, "The processing of Zuota," Journal of Medicine \& Pharmacy of Chinese Minorities, vol. 5, p. 40, 2007.

[6] Z. Wang, "The reinterpreting of Tibetan medicine essence 'Zuota,' Health Word (Academic Edition), vol. 4, no. 9, pp. 8485, 2010.
[7] Ban-ma-cai-ren, "Discussing the processing technology of Zuota from the perspective of chemistry," Journal of Medicine \& Pharmacy of Chinese Minorities, vol. 7, pp. 62-63, 2013.

[8] Ga-ma-qu-pei, Tu-deng-ge-sang, and Ge-qiong, "The processing method of Mercury medicinal powder (Zuotai)," China, Patent, 88107006.8, 1988.

[9] Kan-zhao-ben, "An introduction of Zuotai in Tibetan patent medicine," China Journal of Chinese Materia Medica, vol. 38, no. 10, pp. 1621-1623, 2013.

[10] C. Li, Leng-beng-cai-rang, Suo-lang, Gong-bu-dong-zhi, Y.-Z. $\mathrm{Du}$, and L.-X. Wei, "The chemical and structural analysis of Tibetan medicine Fanshi," Spectroscopy and Spectral Analysis, vol. 32, no. 1, pp. 248-251, 2012.

[11] Dou-ga, "The toxicity evaluation of Tibetan medicine Zuotai and its compound preparations," Journal of Qinghai Junior Teachers's College (Education Sciences Edition), vol. 4, pp. 72-75, 2005.

[12] Yu-tuo Yuan-dan-gong-bu, Si Bu Yi Dian (Four Medical Codes), Shanghai Science and Technology Press, Shanghai, China, 1987.

[13] B.-S. Yang, Jiang-ji-cun, Jiang-yong et al., "The effect characteristics of mercury and safety evaluation Tibetan medicine Zuota," Tibetan Studies, vol. 1, pp. 74-79, 2004.

[14] G.-Y. Zhang, D.-P. Wang, C. Li, H.-M. Zhu, L.-X. Wei, and Y.-Z. Du, "The chronic accumulation of mercury in Tibetan Medicine Zuotai (gTso thal)," Lishizhen Medcine and Material Medica Research, vol. 23, no. 9, pp. 2146-2147, 2012.

[15] H.-M. Zhu, L.-X. Wei, Y.-Z. Du, D.-P. Wang, and C. Li, "Preliminary study on the toxicity in mice of Tibetan Medicine Zuotai under chronic administration," Lishizhen Medcine and Material Medica Research, vol. 24, no. 8, pp. 2022-2024, 2013.

[16] C. Li, D.-P. Wang, Duo-jie et al., "Non-clinical safety evaluation of tibetan medicine zuotai and preliminary clinical safety study of its compound preparation dangzuo," China Journal of Chinese Materia Medica, vol. 39, no. 13, pp. 2573-2582, 2014.

[17] Y. Zeng, S.-M. He, Y. Liu, and Y. Zhang, "Portion study on the central nervous pharmacology effects of Tibetan medicine Zuota," Journal of Sichuan of Traditional Chinese Medicine, vol. 23, no. 11, pp. 33-34, 2005.

[18] E.-N. Jiang, C.-G. Zhang, J.-H. Wang et al., "The study on the main pharmacodynamic actions of Tibetan Medicine Zuotai," Lishizhen Medcine and Material Medica Research, vol. 20, no. 8, pp. 3-4, 2009.

[19] Sang-ji-duo-jie and Gong-ga-luo-bu, "Quality control methods and new usage of a kind of the product processed Tibetan medicine," China, Patent, 200810093949.5, 2008.

[20] Z.-J. Chen, X.-L. Pu, W.-H. Li, K.-Z. Wu, G.-W. Lan, and J. Cui, "The influence on Drosophila life of Tibetan medicine Zuota," Lishizhen Medcine and Material Medica Research, vol. 22, no. 2, pp. 422-423, 2011.

[21] T. Zhu, B. Shen, X.-W. Wang, Bian-ba-chi-ren, and G. Yao, “The proliferation of 239 cell promoted by Tibetan Medicine Zuotai through caspase-3," Journal of Medicine \& Pharmacy of Chinese Minorities, vol. 5, pp. 47-49, 2013.

[22] Environmental Protection Agency (EPA), "Tocicological review of hexavalent chromium," in Support of Summary Information on the Integrated Risk Information System (IRIS), EPA, Washington, DC, USA, 1998.

[23] Centers for Disease Control and Prevention (CDC), Chromium Toxicity, Agency for Toxic Substances and Disease Registry Case Studies in Environmental Medicine (CSEM), Course: WB 1466, Original Date: December 18, 2008, Expiration Date: 
December 18, 2011, http://www.atsdr.cdc.gov/csem/chromium/ docs/chromium.pdf.

[24] A. D. Dayan and A. J. Paine, "Mechanisms of chromium toxicity, carcinogenicity and allergenicity: review of the literature from 1985 to 2000," Human \& Experimental Toxicology, vol. 20, no. 9, pp. 439-451, 2001.

[25] J. B. Vincent, "Chromium: is it essential, pharmacologically relevant, or toxic?" Metal Ions in Life Sciences, vol. 13, pp. 171198, 2013.

[26] L.-F. Yan, "Analysis on the microstructure and chemical components of Tibetan medicine Zuotai," China Tibetology, vol. 3, pp. 150-174, 2007.

[27] L.-F. Yan and X.-K. Ma, "Chemical structure analysis on the carbon in Tibetan medicine Zuotai," Chinese Journal of Ethnomedicine and Ethnopharmacy, vol. 9, pp. 1-2, 2010.

[28] G.-W. Lan, Z.-J. Chen, W.-H. Li, K.-Z. Wu, J. Cui, and X.-L. Piao, "Analysis on chemical constituents of Tibetan Medicine Zogta," Lishizhen Medcine and Material Medica Research, vol. 21, no. 12, pp. 3209-3211, 2010.

[29] X.-Y. Zhao, M. Sun, J.-X. Wang et al., "Characterization of Tibetan medicine Zuota by multiple techniques," Bioinorganic Chemistry and Applications, vol. 2013, Article ID 198545, 11 pages, 2013.

[30] H. M. Mansour, Y.-S. Rhee, and X. Wu, "Nanomedicine in pulmonary delivery," International Journal of Nanomedicine, vol. 4, pp. 299-319, 2009.

[31] J. C. Sung, B. L. Pulliam, and D. A. Edwards, "Nanoparticles for drug delivery to the lungs," Trends in Biotechnology, vol. 25, no. 12, pp. 563-570, 2007.

[32] I. Brigger, C. Dubernet, and P. Couvreur, "Nanoparticles in cancer therapy and diagnosis," Advanced Drug Delivery Reviews, vol. 54, no. 5, pp. 631-651, 2002.

[33] S. B. Tiwari and M. M. Amiji, "A review of nanocarrier-based CNS delivery systems," Current Drug Delivery, vol. 3, no. 2, pp. 219-232, 2006.

[34] I. P. Kaur, R. Bhandari, S. Bhandari, and V. Kakkar, "Potential of solid lipid nanoparticles in brain targeting," Journal of Controlled Release, vol. 127, no. 2, pp. 97-109, 2008.

[35] S.-F. Cao and Y.-Q. Liang, "Thermodynamics analysis of the mercuric sulfide dissolved in aqua regia," Journal of Southwest Institute of Technology, vol. 14, no. 1, pp. 71-73, 1999.

[36] R. A. Bernhoft, "Mercury toxicity and treatment: a review of the literature," Journal of Environmental and Public Health, vol. 2012, Article ID 460508, 10 pages, 2012.

[37] J. Liu, J.-Z. Shi, L.-M. Yu, R. A. Goyer, and M. P. Waalkes, "Mercury in traditional medicines: is cinnabar toxicologically similar to common mercurials?" Experimental Biology and Medicine, vol. 233, no. 7, pp. 810-817, 2008.

[38] H.-X. Gao, Multivariate Statistical Analysis of Application, Beijing University Press, Beijing, China, 2005.

[39] X.-S. Fu, X.-H. Liu, R.-C. Lin et al., "X-ray diffraction fourier fingerprint of magnetitum," Chinese Traditional Patent Medicine, vol. 33, no. 10, pp. 1652-1657, 2011.

[40] L.-Y. Xia, S.-G. Shen, Z.-H. Liu, and H.-W. Sun, "Identification of geographical origins of rice with pattern recognition technique by near infrared spectroscopy," Spectroscopy and Spectral Analysis, vol. 33, no. 1, pp. 102-105, 2013.

[41] J. Wu, F.-R. Huang, C.-H. Huang, J. Zhang, and X.-D. Chen, "Study on near infrared spectroscopy of transgenic soybean identification based on principal component analysis and neural network," Spectroscopy and Spectral Analysis, vol. 33, no. 6, pp. 1537-1541, 2013.
[42] Y. Yang and Z.-F. Guan, "Study on the traditional Tibetan medicine and its processing technology," Journal of $\mathrm{MinZu}$ University of China (Natural Sciences Edition), vol. 17, no. 3, p. 83, 2008.

[43] D.-P. Wang, L.-X. Wei, Y.-Z. Du et al., "Study on the method of determination of mercury sulfide in Tibetan Medicine GTso Thal," Lishizhen Medcine and Material Medica Research, vol. 21, no. 8, pp. 1359-1361, 2010.

[44] B.-C. Zhang, M. Peng, P.-J. Guo et al., Research Report of National Tibetan Medicine Development Strategy, Sichuan Science and Technology Press, Sichuan, China, 2003.

[45] S. Zhang, "The comparing between the mercury processing technologies of Hu Guzi and Wujianba.Renqingbei," The Chinese Pharmaceutical Journal, vol. 34, no. 12, pp. 849-850, 1999.

[46] P. C. Ray, The History of Hindu Chemistry, vol. 1, The Bengal Chemical \& Pharmaceutical Works, Calcutta, India, 2nd edition, 1956.

[47] http://www.ihchina.cn/show/feiyiweb/html/com.tjopen.define. pojo.feiyiwangzhan.GuoJiaMingLu.detail.html?id=b4b7636914b8-498c-ba47-bcc8254c5948\&classPath=com.tjopen.define. pojo.feiyiweb.guojiaminglu.GuoJiaMingLu.

[48] K. Y. Win and S.-S. Feng, "Effects of particle size and surface coating on cellular uptake of polymeric nanoparticles for oral delivery of anticancer drugs," Biomaterials, vol. 26, no. 15, pp. 2713-2722, 2005.

[49] T. Jung, W. Kamm, A. Breitenbach, E. Kaiserling, J. X. Xiao, and T. Kissel, "Biodegradable nanoparticles for oral delivery of peptides: is there a role for polymers to affect mucosal uptake?" European Journal of Pharmaceutics and Biopharmaceutics, vol. 50, no. 1, pp. 147-160, 2000.

[50] C. Li, Duo-ji, Zhan-dui, Z.-J. Xia, Y.-Z. Du, and L.-X. Wei, "Chemical and structural analysis of Nengchi Bajin ashes in refining of Tibetan medicine gTSo thal," China Journal of Chinese Materia Medica, vol. 37, no. 13, pp. 1952-1957, 2012.

[51] C. Li, Suo-lang, Ze-ge, Z. Wang, Y.-Z. Du, and L.-X. Wei, "Chemical and structural analysis of Nengchi Bakuang ashes in refining of Tibetan medicine Zuotai," Chinese Journal of Pharmaceutical Analysis, vol. 31, no. 12, pp. 2220-2224, 2011. 

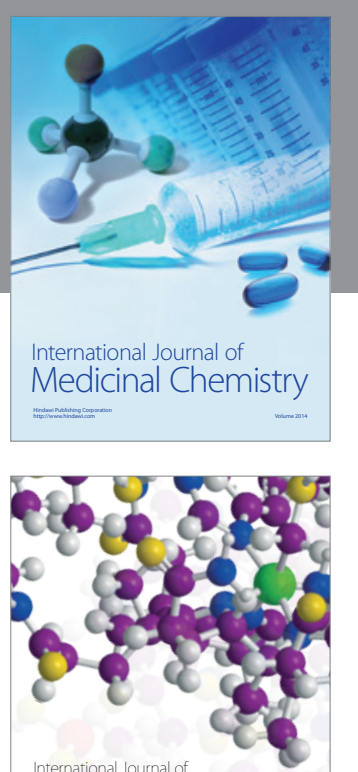

Carbohydrate Chemistry

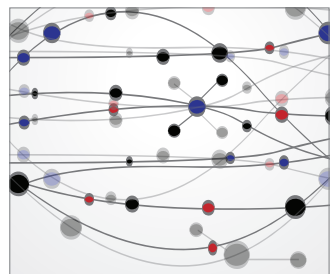

The Scientific World Journal
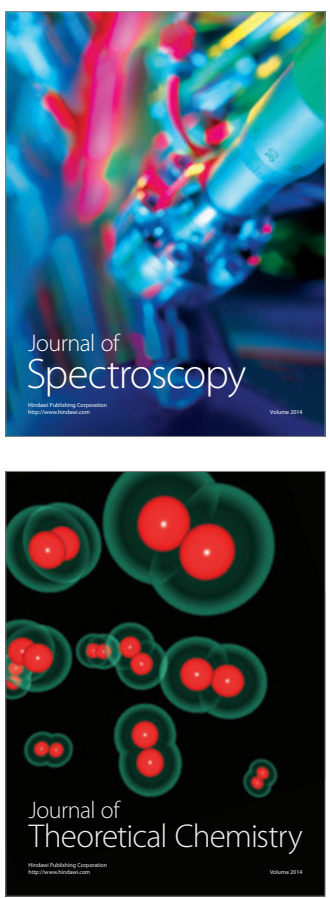
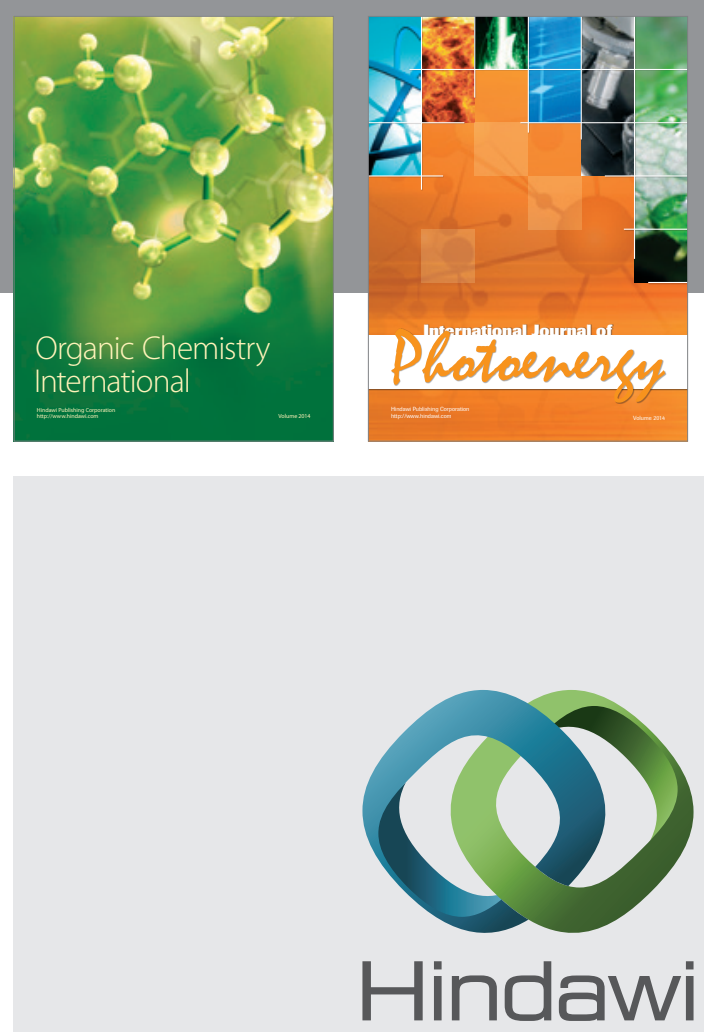

Submit your manuscripts at

http://www.hindawi.com

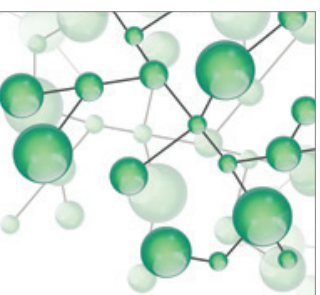

International Journal of

Inorganic Chemistry

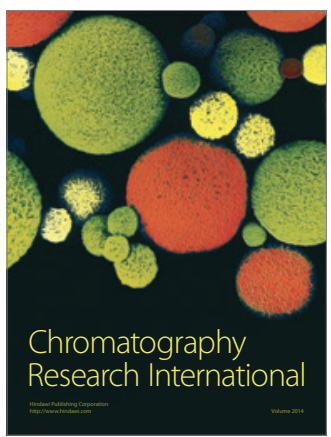

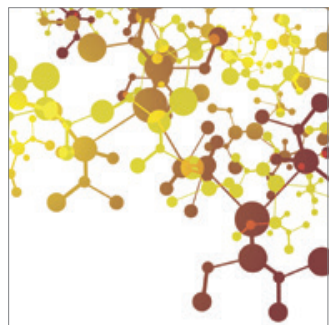

Applied Chemistry
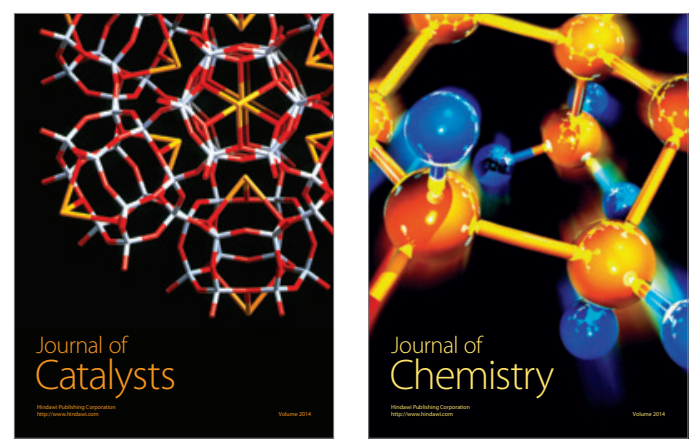
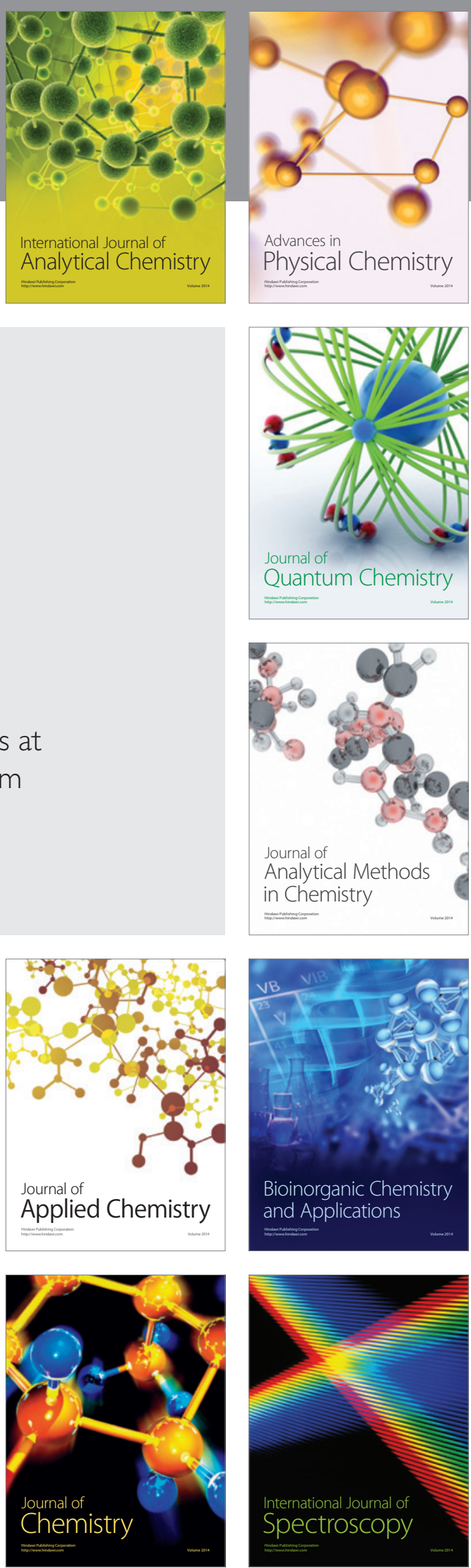